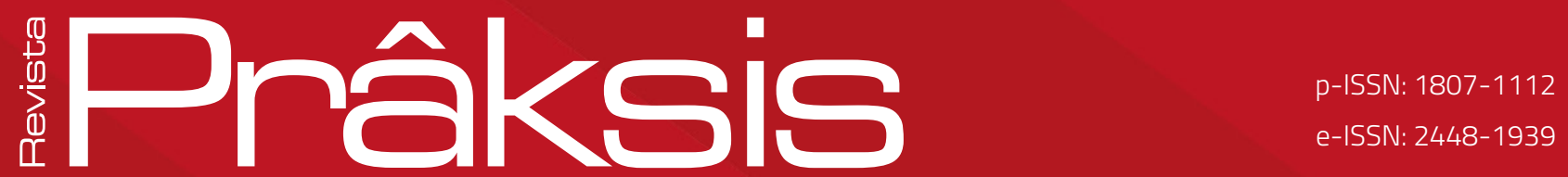

Recebido em: 18 de janeiro de 2019

Aprovado em: 20 de abril de 2019

Sistema de Avaliação: Double Blind Review RPR |a. 16 |n. 2 |p. 07-33| mai./ago. 2019 DOI: https://doi.org/10.25112/rpr.v2i0.1748

\title{
AS ESCREVIVÊNCIAS DAS MARIAS DA CONCEIÇÃO: CONSTRUÇÃO DE NARRATIVAS HISTÓRICAS SITUAdAS
}

\section{CONSTRUCTION OF LOCAL HISTORICAL NARRATIVES OUR LADIES OF CONCEPTION: TO WRITE IS TO LIVE}

\section{Carla de Moura}

Mestre em Ensino de História pela Universidade Federal do Rio Grande do Sul (Porto Alegre/Brasil). Professora na Rede Estadual de Ensino do Rio Grande do Sul (Brasil).

E-mail: carlamoura78@gmail.com.

\section{Fernando Seffner}

Doutor em Educação pela Universidade Federal do Rio Grande do Sul (Porto Alegre/Brasil). Professor na Universidade Federal do Rio Grande do Sul (Porto Alegre/Brasil).

E-mail: fernandoseffner@gmail.com. 


\section{RESUMO}

O texto está construído a partir da longa ambientação dos autores na docência de ensino de História e nas pesquisas acerca da cultura escolar e das questões de raça e gênero. Fruto dessa prolongada inserção, a proposta é compreender a complexidade étnico-racial do território escolar, tomando como base a análise de um recorte de processo pedagógico: a construção de narrativas históricas situadas. Tais narrativas foram elaboradas pelas alunas e alunos de escola de ensino fundamental a partir de um exercício de análise interseccional de fontes históricas primárias, ligadas aos bens culturais aos quais a comunidade escolar atribui sentido de patrimônio. Posteriormente, foi tecida, em documentário audiovisual, uma produção feita com técnicas simples de gravação. 0 trabalho de pesquisa opera com percursos investigativos acerca da História das mulheres de uma vila de classe popular em Porto Alegre, onde a escola se localiza e com quem mantém estreitas relações. $O$ texto cruza marcadores de raça, gênero e classe e avança o conceito de ensino de História situado, valendo-se da noção de escrevivências. É fruto de projeto de pesquisa conjunto dos autores e dialoga com o campo do que tem sido chamado ensino de temas sensíveis, questões socialmente controversas ou passados vivos. Traz excertos de falas de alunos e alunas, e detalha ações pedagógicas feitas com intenção de pesquisa.

Palavras-chave: Ensino de História. Raça. Classe. Gênero. Ensino de história situado.

\section{ABSTRACT}

This paper is written from the authors' long-standing teaching history and research on school culture and issues of race and gender. As a result of this long term insertion, the proposal is to understand the ethnic-racial complexity of the school territory, based on the analysis of a pedagogical process: the construction of "placed on" historical narratives. These narratives were elaborated by the students of elementary school from an exercise of intersectional analysis of primary historical sources, linked to the cultural assets to which the school community attributes a sense of Heritage. Subsequently, they were woven into an audiovisual documentary, produced using simple recording techniques. The research work deals with research on the history of women in a popular class village in Porto Alegre, where the school is located and with whom it maintains close relationships. The text crosses markers of race, gender and class, and advances the concept of teaching of situated History, using the notion of "escrevivências". It is the result of a joint research project of the authors, and dialogues with the field of what has been called teaching of sensitive issues, socially controversial issues or past living. It brings excerpts from student and student speeches, and details pedagogical actions done with research intent.

Keywords: Teaching history. Race. Gender. Class. Placed on historical narratives. 


\section{QUEM SOMOS, DE QUE LUGAR NOS OCUPAMOS, DE ONDE FALAMOS}

Este artigo é fruto de longa inserção dos autores no cotidiano da escola pública em Porto Alegre. A autora principal realizou investigação de mestrado, recolhendo elementos de intensa e continuada trajetória como professora no "chão da escola pública". O segundo autor está inserido em projeto de etnografia de cenas escolares, com observação continuada a escolas de ensino fundamental na cidade. O corpo dessa escrita é fruto da produção da dissertação de mestrado da autora principal ${ }^{1}$. A proposta é compreender a complexidade étnico-racial do território escolar, a partir da análise de um recorte de processo pedagógico: a construção de narrativas históricas situadas. Tais narrativas foram elaboradas pelas alunas e alunos de escola de ensino fundamental a partir de um exercício de análise interseccional de fontes históricas primárias, ligadas aos bens culturais aos quais a comunidade escolar atribui sentido de Patrimônio. Posteriormente, foi tecido o documentário As Marias da Conceição - por um Ensino de História Situado, que se trata de uma produção audiovisual com técnicas rudimentares (celulares e Movie Maker) realizada com as turmas de $8^{\circ}$ e $9^{\circ}$ anos da escola, por meio dos percursos investigativos acerca da História das mulheres da Vila Maria da Conceição, em Porto Alegre. $O$ trabalho cruza marcadores de raça, gênero e classe.

Quem escreve o artigo são duas pessoas não negras. Esse é um aviso que indica atitude ética e de responsabilidade. Mesmo bem-intencionados, falamos de um outro que não somos. Inspiramo-nos em conceitos e autores do pensamento decolonial e, por conta disso, tal situação nos é tensa. Como professora e pesquisadora em uma escola pública de periferia em comunidade afro-brasileira, a autora principal afirma: o Pensamento Feminista Negro não pediu passagem, se impôs. Exigiu honestidade intelectual. Denunciou a insuficiência das categorias de análise fundamentadas em um modelo eurocêntrico, masculino e branco, assim como a categoria "mulheres" no Feminismo (CARNEIRO, 2011).

A autoria do artigo é cis, branca, de classe média, mãe e pai, lésbica e gay, e de docentes. Marcas que afetam nossas escolhas e compreensões. Em um dossiê dedicado ao protagonismo negro, estas não são informações para nota de rodapé. Nossas trajetórias trazem implicações duradouras com alunos e alunas, escola, comunidade escolar, reflexão em educação. A implicação revela caminhada coletiva, e aqui ressaltamos a coautoria da comunidade escolar, agradecemos as aprendizagens e pedimos licença para compartilhar essas histórias. A Escola Estadual de Ensino Fundamental Santa Luzia, local de trabalho da autora principal desde 2012, nasceu comunitária, em 1959, em uma entre tantas "vilas de malocas" surgidas

\footnotetext{
${ }^{1}$ Texto da nota de rodapé escondido de modo a permitir avaliação cega do artigo. Será reintroduzido o texto da nota em caso de aceitação do artigo.
} 
na Porto Alegre pós-enchente de 1941. Permaneceu uma escola pequena, de ensino fundamental, e, não diferente de outras escolas públicas de periferia, carente de recursos financeiros, materiais e humanos. Sua matrícula em 2017 atinge 218 alunos, cerca de $80 \%$ oriundos da Vila Maria da Conceição.

A Vila Maria da Conceição cresceu em torno do local onde, em 1899, ocorreu um crime hediondo. A jovem imigrante alemã Maria Francelina Trenes foi degolada por seu amásio, o soldado da brigada militar Bruno Bicudo. A vila, por muito tempo conhecida como "Maria Degolada", tem nessa história seu mito fundador. Entre as versões recorrentes está a afirmação de que Maria Francelina era prostituta. Entretanto, a comunidade transformou a suposta "puta" em santa, ergueu uma gruta em sua homenagem e atribui a ela inúmeras graças atendidas. 0 que se sabe sobre a Vila Maria da Conceição através dos jornais é que se trata de um território de tráfico de drogas. As famílias vivem no fogo cruzado, em meio às guerras entre as facções do tráfico e à violência policial nas ruas, invadindo as casas. As estatísticas de genocídio da população jovem e negra ali têm nome e endereço, muitas vezes são parentes e amigos. Em meio a esse contexto proliferam as mães de criação, tias, avós ou até mesmo vizinhas ou amigas que assumem as crianças cujos pais morreram ou estão presos. Esta é também uma entre outras razões pelas quais muitas vezes as mulheres criam seus filhos sozinhas.

O que os jornais não dizem sobre a Vila Maria da Conceição é que é uma comunidade sensível, criativa, solidária, alegre e que guarda consigo parte da identidade negra do Rio Grande do Sul. Essa identidade se expressa principalmente através da religiosidade e da música. Os tambores são a marca do morro. A qualquer hora do dia ou da noite batem tambores na Conceição, seja nos ensaios da Academia Samba Puro ou da Academia de Samba Realeza, seja nas casas de religião de Matriz Africana, no Bar do Ricardo ou no samba de beco. As crianças aprendem a percussão batucando em baldes e caixas, misturando samba com funk, enquanto a velha guarda traz as lembranças de um tempo que não volta mais, do velho samba de raiz afrogaúcha movido a tambor de sopapo.

\section{DO MODO COMO TRABALHAMOS E DE NOSSOS REFERENCIAIS TEÓRICOS}

A construção das narrativas históricas situadas é uma etapa importante do nosso percurso pedagógico e partiu dos registros do exercício de análise interseccional de fontes históricas nos diários de campo das alunas e alunos. Em parceria com a comunidade escolar, com o APERS - Arquivo Público do Estado do Rio Grande do Sul - e com o Arquivo Municipal Moysés Vellinho, realizamos levantamento de fontes históricas, ponto de partida para a investigação. As alunas e alunos interrogaram quatro conjuntos de documentos. Um inventário (1882) e 12 cartas de Liberdade (1863-1882) foram pesquisados pelos dois grupos que se dedicaram a estudar a ancestralidade da presença negra no bairro Partenon, onde a Vila 
Maria da Conceição fica localizada. 0 terceiro grupo investigou o processo crime de Maria Francelina Trenes, a Maria Degolada (1899). Por fim, o último grupo explorou a história da Pequena Casa da Criança, em matérias do jornal Zero Hora (1963-1986) e no livro Miséria quem te gerou? (1964), da Irmã Nelly Capuzzo. Esses bens culturais foram tombados simbolicamente como Patrimônio da Comunidade em momento anterior a este trabalho².

Registramos todo o processo com câmeras de telefone celular: entrevistas de História Oral, espaços com significado de Patrimônio para a comunidade e visitas a Museus e Arquivos para a exploração das fontes históricas. O convite foi para uma análise interseccional dessa documentação pelas alunas e alunos, ou seja, que considerasse os marcadores sociais de raça, gênero e classe ${ }^{3}$, e refletisse sobre como estes operam nas condições de possibilidades de existência de indivíduos e grupos. Posteriormente, os estudantes realizaram a construção de narrativas históricas situadas a partir da filmagem da explicação das fontes históricas analisadas, utilizando as mais diversas linguagens: textos, teatro, música, dança e desenho. Propomos aqui pensar como essas narrativas históricas são atravessadas pelos seus lugares de fala, constituindo-se em Escrevivências ${ }^{4}$, por meio dos fragmentos do documentário As Marias da Conceição - Por um Ensino de História Situado, nos quais as alunas e alunos explicam os documentos por eles investigados.

Lugar de Fala é uma categoria forjada por intelectuais negras e utilizada para garantir que vozes dissonantes sejam escutadas em meio a existência de um regime discursivo dominante. A filósofa Djamila Ribeiro (2017) convoca toda essa tradição intelectual para situar esse conceito. É ferramenta útil na aula de História. Amplamente utilizado e também criticado no debate público, quem reivindica a categoria

\footnotetext{
20 momento anterior a esta pesquisa é o Projeto de Educação Patrimonial O Poder da Memória desenvolvido na escola entre 2012 e 2014. Ver em: <www.opoderdamemoria.blogspot.br>.

${ }^{3}$ A interseccionalidade (CRENSHAW, 2016) é uma ferramenta de análise de enorme complexidade que permite pensar a distribuição dos acessos e violências (RIBEIRO, 2017) a partir dos cruzamentos dos mais diversos marcadores sociais: raça, etnia, gênero, sexualidade, classe, geração, deficiência, etc. A opção por dar ênfase aos marcadores raça, gênero e classe não excluiu outras abordagens ao longo do processo pedagógico. No entanto, no exercício de análise interseccional de fontes históricas, diante da complexidade do empreendimento a ser realizado com estudantes de Ensino Fundamental, nos detivemos a tais marcadores levando em consideração dois aspectos: o destaque aos marcadores raça, gênero e classe pelas intelectuais negras cujas produções aportam esta pesquisa; e a intencionalidade em contribuir com o protagonismo das meninas negras a partir da ação pedagógica.

4 Termo cunhado pela escritora negra Conceição Evaristo (2017). Em entrevista para a Revista Nexo, a autora explica: "As nossas escrevivências contam as nossas histórias a partir das nossas perspectivas, é uma escrita que se dá colada à nossa vivência, seja particular ou coletiva, justamente para acordar os da Casa Grande". Entrevista disponível em: <https://www.nexojornal.com. br/entrevista/2017/05/26/Concei\%C3\%A7\%C3\%A3o-Evaristo-\%E2\%80\%98minha-escrita-\%C3\%A9-contaminada-pela-condi\%C3\%A7\%C3\%A3o-de-mulher-negra\%E2\%80\%99>. Acesso em: 15 nov. 2018.
} 
Lugar de Fala são as chamadas minorias. As críticas, por sua vez, vêm tanto da direita quanto da esquerda política, assim como dos meios acadêmicos. 0 aspecto central da crítica dirigida ao uso desse conceito é de que se liga aos movimentos identitários e assim, do ponto de vista de quem dirige a crítica, é considerado essencialista, sem refinamento teórico, a-histórico, além de retrógrado politicamente. A questão é que as identidades foram criadas dentro da lógica colonial e o colonialismo articula essas identidades de modo a privilegiar certos grupos em detrimento de outros. Segundo Alcoff, "O colonialismo cria e reifica as identidades como meio de administrar povos e estabelecer hierarquias entre eles" (ALCOFF, 2016, p. 137 apud RIBEIRO, 2017, p. 31). Isso define quem é escutado quando fala e quais conhecimentos são considerados legítimos. Mais do que isso, estes, cuja fala tem legitimidade, têm poder para falar pelos outros e falar sobre os outros usando a si próprios como parâmetro, julgando-se, desse modo, universais (ALCOFF, 2016 apud RIBEIRO, 2017, p. 31).

Há pessoas que dizem que o importante é a causa, ou uma possivel voz de ninguém como se não fôssemos corporificados, marcados e deslegitimados pela norma colonizadora. Mas, comumente, só fala na voz de ninguém quem sempre teve voz e nunca precisou reivindicar sua humanidade (RIBEIRO, 2017, p. 90).

Nesse sentido, um projeto de descolonização epistemológica denuncia toda e qualquer pretensão de objetividade científica pautada na neutralidade, imparcialidade e universalidade. Passa pela importância epistêmica das identidades, pois apontam para o fato de que as localizações sociais proporcionam experiências sociais diferentes e desiguais. Essa operação dialoga com a noção de identidade narrativa. Sobre esta, Anhorn (2012) explica que não se trata mais de apenas se perguntar o que esta história nos conta, mas também quem conta essa história. Segundo a autora,

[...] esta forma de conceber a questão das identidades nos autoriza reconhecer que os fios das tramas traçadas são seletivos e que, ao serem tecidos, eles se posicionam em relação a outras tramas, a outras identidades narrativas já existentes e muitas vezes concorrenciais (ANHORN, 2012, p. 136).

Partindo desse pressuposto, poderíamos pensar que a acusação de "identitário", que se faz aos movimentos que questionam a suposta universalidade, recai sobre os acusadores, na medida em que foram eles que racializaram os sujeitos e estabeleceram as regras das relações de gênero em benefício simbólico e material próprio. Ao contrário, os movimentos identitários buscam justamente denunciar as desigualdades na distribuição das violências e dos acessos provocados por essa diferenciação. As intelectuais negras aprenderam e dominaram a língua do colonizador, mas o fizeram antropofagicamente. Criando ferramentas de falar que possibilitam que uma multiplicidade de vozes dos grupos historicamente 
invisibilizados sejam ouvidas. Desvelando o discurso único e autorizado que se pretende imparcial. Lélia Gonzalez (1983, p. 225) anuncia a potência da autorrepresentação:

E o risco que assumimos aqui é o do ato de falar com todas as implicações. Exatamente porque temos sido falados, infantilizados (infans, é aquele que não tem fala própria, é a criança que se fala na terceira pessoa, porque falada pelos adultos), que neste trabalho assumimos nossa própria fala. Ou seja, o lixo vai falar, e numa boa.

\section{AS FALAS DAS ALUNAS E DOS ALUNOS E NOSSO DIÁLOGO COM AS TEORIAS}

Todo o conhecimento é situado. A História é um saber eurocêntrico e legitimado. Interessa nesta parte da pesquisa compreender como este saber, no âmbito da Educação, pode ser interpelado por narrativas situadas nos lugares de fala das alunas e alunos de uma comunidade negra. Na primeira aula dessa etapa, o alunado releu em grupos seus roteiros de análise interseccional das fontes históricas e seus diários de campo, com a preocupação de definir as informações mais importantes para "contar esta História". Essa foi uma aula dedicada à seleção e encadeamento de informações retiradas das fontes históricas pesquisadas e das reflexões proporcionadas pela Análise Interseccional da documentação, com o objetivo de produzir uma narrativa histórica. No diário de campo, um aluno negro registrou neste dia:

Nós somos crias das Docas das Frutas, Colônia Africana. Fomos despejados, então meus ancestrais subiram o morro junto com a nossa querida Irmã Nelly. Cidade Baixa onde se escapam os negro fujão, tudo isso ajuda a criação da nossa querida Vila Maria da Conceição e assim da nossa Samba Puro.

A História étensionada pela ancestralidade, mostrando a presença de uma epistemologia afrocentrada. Na mesma direção, a expressão "somos crias" liga-se a uma noção de família ampliada, a exemplo das famílias de santo e dos saberes de terreiro, que se estendem nas relações comunitárias. Ao mesmo tempo, todo um conjunto de referências acerca da História do povo negro na cidade de Porto Alegre foi selecionado e ressaltado pelo aluno. Ao enunciar "Nós somos", o aluno evoca, através da experiência compartilhada dos despejos e das fugas, o lócus social dos sujeitos. Após esse trabalho, as alunas e alunos planejaram e ensaiaram suas narrativas utilizando as mais diferentes linguagens: produção de textos, esquemas, músicas, teatro, desenho. Nessas aulas, os grupos trabalharam no pátio da escola, que é um espaço cheio de árvores e com uma linda vista da cidade. Aqui a questão é estética e diz respeito a como esta História será contada. Musicalidade e Corporeidade são Valores Civilizatórios Afro-brasileiros (TRINDADE, 2010) e se fazem presentes nas formas de expressão das alunas ealunos. A criação de movimentos, ritmos, formas, fornecem uma centralidade no corpo que narra, expressão do lugar de fala das narradoras e narradores. 
Assim:

No que tange às dimensões do corpo, a pedagogia das encruzilhadas o compreende como suporte de memórias e saberes. Essa consideração está presente na noção de incorporação, conceito que circunscreve e credibiliza a dimensão dos saberes praticados, partindo do pressuposto de que todo saber, para se manifestar, necessita de um suporte físico. Assim, o suporte físico-corpo é, por sua vez, parte do saber; não há separação entre eles. $\mathrm{O}$ suporte físico - corpo humano ou outra materialidade - é incorporado por um efeito, um poder que o 'monta' (RUFINO, 2015, p. 13).

O autor explica que "[...] a racionalidade moderna ocidental é decapitada e assombrada pela má sorte de ter o corpo (bara) deslocado da cabeça (ori)". A maquinaria escolar (VARELA; ALVAREZ-URIA, 1992), como tecnologia de domesticação de corpos e imposição de um modelo civilizatório, tem papel fundamental nessa problemática. O disciplinamento dos corpos tem um método: classes alinhadas, ambiente silencioso, organizado, limpo, no qual o professor ensina e o aluno aprende. Necessariamente, o trabalho com música, dança, teatro, jogos traz o corpo para o centro do processo ensino-aprendizagem, "bagunça" os espaços e tempos da escola, funciona como um movimento "ludista" contra a maquinaria escolar. Um projeto de Educação Antirracista e Decolonial, passa pelo reconhecimento do corpo como lugar do conhecimento, na medida em que todo saber só é possível quando praticado, ou seja, incorporado (RUFINO, 2015).

Os grupos que trabalharam com a Academia de Samba Puro e com as religiões de Matriz Africana, portanto com o inventário e com as cartas de liberdade, utilizaram bonecos recortados de papel para visualizar os sujeitos apresentados pela documentação. Também fizeram um desenho em que as cinco mulheres negras, consideradas pelas alunas como protagonistas da narrativa, foram representadas: Henriquieta, Virgilina, Malvina, Olímpia e América. O grupo que trabalhou com o processo crime do assassinato de Maria Francelina Trenes, a Maria Degolada, decidiu dramatizar a História narrada pelo documento, utilizando o pátio da escola como cenário, já com o objetivo de, no momento da edição, usar efeito preto e branco como "nos filmes de antigamente". O grupo que trabalhou com as matérias de jornal sobre a Irmã Nelly e a Pequena Casa da Criança criou um rap para a denúncia de genocídio da população jovem negra, feita pela Irmã aos jornais, e escreveu um texto.

As alunas e alunos realizaram as apresentações para filmagem. Também gravamos grupos de alunas explicando as fontes históricas pesquisadas. Essas gravações foram por vezes de conversas mais espontâneas, mas também foram realizadas as leituras de textos previamente escritos ou explicações ensaiadas, dividindo o que cada integrante do grupo iria falar. Aqui elas estão registradas integralmente e na ordem em que aparecem no documentário As Marias da Conceição - Por um Ensino e História Situado. 
A narrativa das alunas e alunos, no documentário, inicia com a filmagem realizada no banheiro da escola em que uma aluna, com uma vela na mão, diz três vezes Maria Degolada. Nesse momento, outra aluna, vestida como Maria Francelina, aparece no espelho e toca o ombro da colega. Essa é uma história que permeia principalmente o imaginário dos jovens: se falar três vezes Maria Degolada em frente a um espelho, ela aparece. Pois as alunas e alunos decidiram, no processo de edição, que a cena começaria por aí, "é como se a gente estivesse chamando ela para contar a história", alegaram.

A encenação continua no pátio da escola com a História de Maria Francelina Trenes, dialogando de perto com os elementos colhidos no processo crime. A proposta foi inspirada em uma fotografia pertencente ao acervo do Museu Joaquim José Felizardo, de autoria do Lunara, intitulada Amor e Ciúme, do ano de 1900. Na fotografia, um casal conversa embaixo de uma frondosa árvore, e um homem os espia, à espreita, atrás da árvore. A cena inicia com essa imagem: Maria Francelina conversa com um homem enquanto Bruno Bicudo espia atrás de uma árvore. Após essa cena, aparecem dois casais fazendo um piquenique. Maria Francelina se levanta e caminha. Bruno Bicudo vai atrás e a puxa pelo braço. Inicia-se uma discussão em que Bruno Bicudo, com o dedo em riste, grita com a moça e depois a agarra, sacudindo-a pelos ombros. Maria se defende com uma acha de lenha. A cena é cortada e aparece o rosto de Bruno Bicudo, que, com o afastar da câmera, mostra estar com um facão na mão. 0 assassinato foi representado por um lento movimento com um facão executado pelo aluno que interpretou Bruno Bicudo. Entre as cenas, apareciam os textos das testemunhas do processo e do jornalista do jornal $A$ Gazetinha, que registrou o caso.

As alunas e alunos propuseram usar efeito preto e branco na gravação e voltar ao colorido no final da encenação, para ressaltar o sangue representado por um lenço vermelho no pescoço da aluna que desempenhou o papel de Maria Francelina. No documentário, após a teatralização da cena do crime, as alunas explicam a documentação por elas analisada5:

A.: 0 que nos chamou atenção no processo criminal da Maria Degolada foi que durante o depoimento das testemunhas apenas homens testemunharam o ocorrido, sendo que uma delas apontou que no local do crime haviam homens e mulheres. Porém elas não foram ouvidas na época e isso nos chamou muito atenção e nos deixou pensando: o que será que elas teriam dito se elas tivessem sido ouvidas? Hoje em dia esse processo de um homem matar uma mulher é chamado de feminicídio e tem uma taxa muito alta de feminicídio hoje em dia. Em que homens simplesmente matam as suas namoradas ou as suas ex-namoradas por ciúmes, ou por que não aceitam o fim de um relacionamento, ou simplesmente por não

\footnotetext{
${ }^{5}$ As falas das alunas e alunos no documentário As Marias da Conceição: Por um Ensino de História Situado são aqui transcritas e destacadas em moldura a fim de diferenciação das demais referências.
} 
quererem que elas sigam as suas vidas.

As alunas, ao realizar o exercício de análise interseccional do processo crime e perguntarem-se sobre qual o lugar de fala de quem produz os discursos nas fontes históricas, constatam que apenas os homens foram testemunhas no processo. Ao questionar o silenciamento das testemunhas mulheres, a "veracidade" do documento é automaticamente colocada em xeque. As alunas atualizam a explicação usando o conceito de feminicídio, com o qual demonstram compactuar. Enfatizam que o documento apresenta uma perspectiva parcial, e a intencionalidade dos testemunhos passa a ser investigada:

J.: No processo crime, homens, amigos de Bruno Bicudo, falaram que ela agrediu ele com um pedaço de pau e de madeira, desonrou ele falando que ela ia dormir com outro...

A.: Tentando assim justificar o motivo dele ter matado ela, dizendo que era simplesmente a legítima defesa da honra. Como quando, por exemplo, hoje em dia tentam muitas vezes justificar o fato de uma menina ser estuprada dizendo que 'ah ela tava com short curto ela tava pedindo' ou quando dizem 'ela tava andado na rua sozinha essa hora da noite, também tava pedindo, né?'. E isso é uma coisa muito absurda! Porque simplesmente não tem como alguém pedir para ser estuprada. Se ela tava de short curto é porque ela queria estar de short curto.

\section{J.: O corpo é dela!}

A.: Se ela estava andando na rua de noite é porque ela queria! Não é porque ela queria simplesmente ser estuprada. Ela precisava ou ir pra casa, ou ir pro trabalho, ou ela estava indo pra casa de alguma amiga, ou indo pra casa do namorado... Não tem como uma mulher simplesmente chegar e pedir para ser estuprada.

A.: Mas em nenhuma parte do documento se diz que a Maria tinha profissão de prostituta. J.: Sendo que não era verdade!!!

A.: Nada no documento nunca comprovou que ela era de fato uma prostituta, deixando assim que o povo foi incrementando a história, deixando a entender que ela era sim, de fato, uma prostituta. Que ela era barraqueira, que ela batia no cara, que ela sempre discutia, que ela batia de frente com ele... Que ela simplesmente não deixava as coisas passarem batido. Que tinha voz e sabia falar, sabia se defender. Sabia simplesmente ser dona de si própria não deixando que ele interferisse em nada da vida dele.

As alunas questionam se as testemunhas não estariam tentando proteger o assassino, na medida em que todos os depoimentos enfatizam que Maria Francelina bateu no acusado e "Ihe dirigiu chufas", dizendo-Ihe que teria outro com quem dormir naquela noite. Para tanto, utilizam a noção de "Legítima 
Defesa da Honra", evocando o código moral e penal da época. No entendimento das alunas, como nada nas fontes indica que ela realmente tinha a profissão de prostituta, estes depoimentos, que enfatizam que ela era "barraqueira", somado ao falatório do povo, que foi "incrementando a história", são responsáveis pela fama de prostituta de Maria Francelina. As alunas se aproximam, a partir do marcador social "mulher", de Maria Francelina Trenes e identificam nas relações sociais do presente que os fatores que levaram ao feminicídio permanecem atuantes. As meninas utilizam todo um aporte das discussões feministas da contemporaneidade para discutir a "fama de puta" atribuída às mulheres cuja independência se opõe aos preceitos machistas. Fazem isso através de expressões como "o corpo é dela", para comparar a tentativa por parte dos soldados, "amigos de Bruno Bicudo", de justificar a ação do colega com os discursos que afirmam que, se uma mulher está de "roupa curta" ou "na rua sozinha", "está pedindo para ser estuprada", e denunciam: "é um absurdo isso!".

Para as alunas, Maria Francelina era uma mulher que tinha voz, sabia falar e se defender, por isso foi assassinada. Nas suas explicações, as alunas reconhecem que a violência física e simbólica (no campo das representações) às mulheres, assim como as resistências, são uma experiência social compartilhada pelas mulheres em diferentes períodos históricos. A questão de gênero na explicação dos documentos, do lugar de fala das adolescentes, é aportada nas epistemologias feministas. No entanto, Sueli Carneiro (2011, p. 2) nos convida a aprofundar a análise:

Se o feminismo deve liberar as mulheres, deve enfrentar virtualmente todas as formas de opressão. A partir desse ponto de vista, é possivel afirmar que um feminismo negro, construído no contexto de sociedades multirraciais, pluriculturais e racistas - como são as sociedades latino-americanas - tem como principal eixo articulador o racismo e seu impacto sobre as relações de gênero, uma vez que ele determina a própria hierarquia de gênero em nossas sociedades.

Dessa forma, ao operar a interseccionalidade, as alunas foram convidadas a pensar sobre o marcador social "raça", na documentação. Sueli Carneiro (2011) afirma que o horizonte da atuação das intelectuais negras é a possibilidade de construção de um modelo civilizatório humano, fraterno e solidário, em que a diferença seja vivida como equivalência e não mais como inferioridade. No entanto, a autora chama a atenção para o fato de que, para que haja igualdade de direitos, é preciso que as diferenças não sejam invisibilizadas ou diluídas - é preciso fazê-las existir. Assim, ao propor Enegrecer o Feminismo, convida ao posicionamento diante das especificidades que atravessam as vidas das mulheres negras:

Enegrecer o movimento feminista brasileiro tem significado, concretamente, demarcar e instituir na agenda do movimento de mulheres o peso que a questão racial tem na configuração, por exemplo, das políticas demográficas, na caracterização da questão da 
violência contra a mulher pela introdução do conceito de violência racial como aspecto determinante das formas de violência sofridas por metade da população feminina do país que não é branca; introduzir a discussão sobre as doenças étnicas/raciais ou as doenças com maior incidência sobre a população negra como questões fundamentais na formulação de políticas públicas na área de saúde; instituir a crítica aos mecanismos de seleção no mercado de trabalho como a 'boa aparência', que mantém as desigualdades e os privilégios entre as mulheres brancas e negras (CARNEIRO, 2011).

É com a intenção de enfatizar essas desigualdades que, no documentário As Marias da Conceição Por um Ensino de História Situado, após essa primeira explicação do documento, outro grupo de alunas aparece fazendo o seguinte questionamento:

\section{L.: Maria Degolada...}

A.: Maria Degolada...

VG.: Maria Degolada...

R.: Se tu fosse negra...

AC.: ...Tu seria uma santa?

Essa pergunta foi elaborada a partir das aulas sobre as categorias de análise do Feminismo Negro aplicadas no exercício de análise interseccional de fontes históricas. Houve uma discussão em que levantamos hipóteses para o fato de o assassinato de Maria Francelina Trenes ter causado tamanha comoção, ao ponto de entrar para o imaginário e posteriormente para a História da cidade de Porto Alegre. No registro em diário de campo, uma das alunas afirmou: "Se fosse uma mulher negra não teria gerado história". No documentário, a afirmação é reelaborada e transformada em pergunta. Mas elas explicam o porquê da indagação:

N.: Estamos fazendo essa pergunta porque chegamos à conclusão que, nesse momento que a gente ta aqui, tem uma mulher sendo executada, uma mulher negra, entendeu? E a gente tem que dar um basta nisso!

K.: E que assim ó: se um negro de periferia morre não fazem nada, agora se for um branco lá do outro país, aí eles querem fazer, ir lá, lutar pelos bagulho...

N.: Todo mundo se comove, entendeu? Todo mundo se comove! Mas quando é uma mulher negra...

K.: Por que com o negro não fazem? 
L.: Porque vidas brancas valem mais do que vidas negras. Porque quando um branco morre, vai pro jornal, vai pra revista, vai pra tudo que é lugar. Já se é um negro, as pessoas nem se perguntam o porquê que ele morreu.

A denúncia das alunas é pesada e demonstra que suas reflexões são perpassadas pelo seu lugar de fala, suas possibilidades de protagonismo, pois todas elas já perderam pessoas queridas, geralmente muito jovens, e conhecem de perto as políticas de genocídio da população negra. A aluna que afirma que "quando é um branco lá do outro país, aí eles querem lutar pelos bagulho", faz referência a uma discussão que tiveram minutos antes da gravação, em que comentavam sobre os filtros de bandeira da França no Facebook após o atentado terrorista naquele país. Essas manifestações não fazem o menor sentido para as alunas que denunciam a comoção seletiva. Outra aluna complementa de forma sofisticada a reflexão da colega, evocando a discussão trazida pela campanha civil lançada nos Estados Unidos, mas com caráter internacionalista, que tem por lema a frase: Black Lives Matter, ou seja, "Vidas Negras Importam". Cabe aqui ressaltar que, quando a aluna afirma que "vidas brancas valem mais que vidas negras", ela lança um olhar para a branquitude, para a classe média sem empatia que compactua com o genocídio, seja pelo silêncio, seja pela eloquência com que repete que "bandido bom é bandido morto", para o Estado que assassina e para os ricos que exigem tais assassinatos. Cabe, ainda, dizer que essas vidas perdidas são profundamente sentidas pelos familiares, amigos, vizinhos ${ }^{7}$. As alunas continuam sua fala enlaçando a denúncia do genocídio da população jovem negra com a questão das representações. Quem pode falar? Quem é escutado quando fala? Como os moradores de periferia são falados por outros?

G.: Se ele morreu é porque é traficante, mora na vila...

VG.: E devem, e devem!

L.: Ou é uma mãe que morreu pra defender o filho...

K.: E Sabe por quê? Sabe por quê? Isso é, faz parte do Feminismo Negro!

R.: Jogam tudo pra debaixo do tapete!

N.: É! Pra debaixo do tapete!

\footnotetext{
${ }^{6}$ Encontram-se informações detalhadas sobre o movimento em: <https://blacklivesmatter.com/>.

7 Um menino, aluno da escola, foi assassinado em 2017. Ele tinha treze anos e era muito querido por todos. Os colegas, até o final daquele ano, deixaram a classe que ele costumava ocupar vazia. Ninguém sentava naquele lugar. As letras que iniciavam o seu nome acompanham agora, também, o nome dos colegas nos perfis de Facebook como uma sigla. Estão também marcadas na camisa da bateria da Escola de Samba. Nós sentimos muito a falta do WGR! Vidas Negras importam!
} 
G.: É, eles não querem saber a história real, eles tentam inventar uma história.

L.: Sendo que se morreu era porque era traficante, era de periferia,

R.: Era ladrão...

L.: Mas eles não vão dizer que era porque tava defendendo o filho no meio de um tiroteio...

As meninas pela primeira vez evocam o Feminismo Negro. Essa referência, no entanto, não é utilizada por elas para apontar o machismo e o sexismo, mas para desvelar o racismo. O Feminismo Negro é ressaltado como ferramenta para falar, é o que torna possível falar do que "é colocado para debaixo do tapete". Falar da história real, não da história "por eles inventada". Imaginemos Lélia Gonzalez conversando com as alunas:

A primeira coisa que a gente percebe, nesse papo de racismo é que todo mundo acha que é natural. Que negro tem mais é que viver na miséria. Por quê? Ora, porque ele tem umas qualidades que não estão com nada: irresponsabilidade, incapacidade intelectual, criancice, etc. e tal. Daí, é natural que seja perseguido pela polícia, pois não gosta de trabalho, sabe? Se não trabalha, é malandro e se é malandro é ladrão. Logo, tem que ser preso, naturalmente. Menor negro só pode ser pivete ou trombadinha, pois filho de peixe, peixinho é. Mulher negra, naturalmente, é cozinheira, faxineira, servente, trocadora de ônibus ou prostituta. Basta a gente ler jornal, ouvir rádio e ver televisão. Eles não querem nada. Portanto têm mais é que ser favelados (GONZALEZ, 1983, p. 226).

A ironia refinada de Lélia Gonzalez para trazer à tona todo o discurso da branquitude sobre os sujeitos negros e de como esses discursos são tratados como dado natural, amplamente divulgados pelos veículos de comunicação, conflui com as falas das estudantes. A questão é que essas representações transbordam o imaginário e incidem no real na medida em que determinam como os sujeitos se veem e são vistos na sociedade. O Feminismo Negro, na fala das alunas, seria um instrumento "para defender os negros" justamente dos efeitos práticos de tais representações:

K.: E que feminismo negro não é só para as mulheres, também são para os filhos delas pra defender eles de...

VG.: De ir pro colégio tomar um paredão. De tu ta lá e falar que tu é do tráfico. De tu usar uma roupa bagaceira e falarem que tu é fumante, que tu é drogado, que tu te droga que tu rouba, que tu é tudo!

K.: E o Feminismo Negro é pra ajudar os negros a se...

VG.: A ser igual a todo mundo! Porque ninguém é melhor do que ninguém! Branco é Branco! 
Negro é Negro! Mas os negros sofrem e...

K: Sofrem mais que os brancos, porque é isso.

Na intersecção com o gênero é evidente na narrativa das alunas que os homens negros não ocupam o mesmo lugar de privilégio dos homens brancos. As alunas, ao afirmarem que o "Feminismo Negro não é só para as mulheres, mas também para os filhos delas", ressaltam que o sofrimento das mulheres negras é também causado pelo genocídio da população jovem negra, majoritariamente masculina, e pelas políticas de encarceramento a que a população negra é exposta. Djamila Ribeiro (2017) ressalta que homens negros estão inclusive abaixo das mulheres brancas na pirâmide social. Diferenciar os homens negros dos homens brancos e denunciar a violência a que homens negros estão expostos é um tema presente na produção intelectual das mulheres negras:

A percepção de que o homem deve ser, por exemplo, o principal provedor do sustento da família, o ocupante das posições mais valorizadas do mercado de trabalho, o atleta sexual, o iniciador das relações amorosas, o agressivo, não significa que a condição masculina seja de superioridade incontestável. Essas mesmas imagens cruzadas com o racismo reconfiguram totalmente a forma como os homens negros vivenciam gênero. Assim, o negro desempregado ou ganhando um salário minguado é visto como o preguiçoso, o fracassado, o incapaz. 0 atleta sexual é percebido como um estuprador em potencial, o agressivo torna-se o alvo preferido da brutalidade policial (BAIRROS, 1995, p. 461).

O Lugar de Fala, neste caso, apresenta-se como ferramenta para denúncia das atrocidades vivenciadas de forma compartilhada na comunidade. As alunas, ao operarem a Interseccionalidade, apuraram seus olhares sobre os processos pelos quais se dá a distribuição dos acessos e violências (MOÇAMBA apud RIBEIRO, 2017). As meninas seguem suas falas:

N.: Por exemplo, vamos falar da morte da Marielle, porque isso é importante de saber, gente. A morte da Marielle foi uma coisa que chocou muito o Brasil, entendeu? Só que, tipo, foi uma coisa velada, entendeu? Eles botaram embaixo do tapete. Eles esconderam! Não se passa mais hoje a morte dela na TV, entendeu?

K.: E ela morreu lutando pelos nossos direitos, dos negros, a deputada.

N.: Santa pra nós é a Marielle! Que morreu lutando pelos nossos direitos e agora nós vamos lutar por ela!

K.: Vamos lutar para todos os negros né, porque a gente juntos, a gente somos um só! 
As alunas recordam e denunciam a execução da vereadora e militante dos direitos humanos, Marielle Franco, e concluem: "Santa pra nós é a Marielle, que morreu lutando pelos nossos direitos" e ainda complementam: "E agora nós vamos lutar por ela". A disposição para o enfrentamento da violência racista é demonstrada nessa fala. Mesmo sem ter essa referência, a partir da expressão: "juntos, a gente somos um só", a aluna evoca um importante conceito filosófico africano, o Ubuntu, no Brasil traduzido para "Sou porque somos". Sua fala demonstra novamente a presença da epistemologia afrocêntrica por meio desse conceito potente, que aponta para a coletividade e para o autocuidado:

O ubuntu é, ontologicamente um -dade e não um -ismo enquanto tal está epistemologicamente orientado em direção a construção de um conhecimento que é em sua essência, não dogmático [...]. O ubuntu é um dos conceitos filosóficos e dos princípios organizacionais essenciais das populações que falam a língua Bantu, essas populações precisam, face à globalização econômica, cimentar fortes vínculos de solidariedade, em primeiro lugar entre elas mesmas. Aqui, o desiderato por solidariedade é, de facto, a construção de uma fronteira. Portanto, o raciocínio circunscrito, não é nem um alienígena, nem necessariamente repugnante à filosofia ubuntu. Mas a delimitação de fronteira neste caso é um meio para um fim, e não um fim em si mesmo. As populações falantes de bantu devem permanecer abertas a cooperar com todos os seres humanos do mundo que estejam determinados a substituir o dogma mortal do fundamentalismo econômico pela lógica frutífera do -dade, preferindo a preservação da vida humana através da colaboração à busca estrita do lucro (RAMOSE, 2009, p. 139).

Esse debate entre as alunas demonstra como elas se apropriaram da produção intelectual das mulheres negras, que é profundamente dedicada a trazer para a pauta do dia as questões que colocam vidas negras em risco. $O$ racismo de Estado e as consequentes violações de direitos humanos a que a população negra é exposta no Brasil, assim como suas resistências, são temas centrais nas suas obras e também nas narrativas das alunas. É preciso que se diga que o status de intelectual não livra as mulheres negras de sofrer as violências raciais e de gênero, ao contrário: as torna um alvo. Beatriz Nascimento foi covardemente assassinada em 1995 ao defender uma amiga do marido agressor. Enquanto este texto foi escrito, Marielle Franco, cientista social e vereadora mais votada do Rio de Janeiro, foi executada duas semanas após assumir a função de relatora da Comissão da Câmara de Vereadores criada para acompanhar a intervenção militar das tropas nas periferias de seu estado. Após essa discussão entre as alunas, no documentário As Marias da Conceição: Por um Ensino de História Situado, inicia-se uma cena filmada na Vila Maria da Conceição, na qual as alunas cantam uma música de autoria de uma delas. A música, intitulada Orgulho de ser preta, é um rap e foi criada a partir da aula sobre Feminismo Negro. Aqui, as alunas situam a experiência coletiva de ser negra, e, portanto, seus lugares de fala: 
(F.:)

Eu sinto orgulho de ser preta

E ninguém tira isso

Da minha cabeça

Meu cabelo Black

Só reforça minha natureza

Sim já fui zoada

De cabelo duro e tal

Mas Deus não dorme

Vão pagar por tudo em real

Por todo sofrimento

Que nós pretos passamos juntos

Nós vamos superar juntos

Vão aplaudir todos nós juntos

(K.:)

Nas favelas

Negros morrem

Por desacato à autoridade,

Mas se é branco

Com dinheiro

Responde

Em liberdade

Tô pouco me lixando

Para o que esses brancos falam

Eles querem o nosso mal

E o fim da nossa raça!
(N.:)

A triste realidade

É que o mundo perdido tá

Facção com faç̧ão

Seria melhor se juntar

Ao invés de brigar, claro

Por boca de fumo

Vamos lutar pra conquistar

O nosso lugar no mundo!

(A.C.:)

Novelas e mini séries

Dão mal exemplo

Só tem negro em senzala

Na cozinha

E limpando a sala

Racismo tá em toda parte

Onde quer que cê vá

Comércio, supermercado

Transporte coletivo e pá

(Todas:)

Basta! Chega!

Preconceito sai pra lá!

É os preto no topo

E do topo

Ninguém vai nos tira

Pode até tentar

Mas no topo

Vamos continuar

É os preto no topo!

Após essa música, o documentário passa às imagens da Bateria Cadência do Morro, da Academia Samba Puro. Primeiramente, a bateria mirim tocando na Festa da Consciência Negra daE.E.E.F. Santa Luzia, depois, durante a Marcha Zumbi e Dandara no Dia da Consciência Negra, organizado pelos Movimentos Negros no centro da cidade. Em ambas as filmagens, aparecem alunas e alunos da escola tocando 
instrumentos. A Academia de Samba Puro é uma das maiores expressões da cultura de Matriz Africana no Morro da Conceição. É a prova viva de uma ancestralidade negra, muito valorizada pelas alunas, alunos e comunidade. Os tambores da Samba Puro são o coração do morro. Esse sentimento fica evidente na explicação de um aluno, cujo irmão é Mestre da Bateria:

W.: O nosso grupo pesquisou a história da Samba Puro, mas pra isso foi preciso pesquisar a presença negra no Partenon. Como vocês podem ver no mapa aqui, o Partenon e a Restinga é o lugar onde tem mais casa de religiões em Porto Alegre. Como vocês podem ver aqui nessas fotos, essas imagens são partes da Colônia Africana que foi removida para o Partenon.

O aluno se refere a um mapa da dissertação de mestrado de RECH (2012), no qual, através de um levantamento das Casas de Religião de Matriz Africana da cidade, os bairros Partenon e Restinga são apresentados como aqueles que concentram o maior número de Terreiros. A dissertação traz ainda depoimentos de Pais e Mães de Santo desses bairros, indicando suas bacias nos Bairros Auxiliadora, Mont'Serrat e Rio Branco, ou seja, na Antiga Colônia Africana. Pai Eloir de Ogum, morador da Vila Maria da Conceição, entrevistado no documentário, confirma esse dado. Nascido na rua Pedro Ivo, no bairro Mont'Serrat, recebeu ali seu Axé de búzios e Axé de faca da Mãe Margarida da lansã, sua tia. Abriu sua Casa de Religião em 1967, na Vila Maria da Conceição.

Se lugar de fala é o lugar social, é obviamente uma categoria marcada pela História. A História, como parte da epistemologia dominante, opera diretamente no processo de subalternização de grupos em prol do privilégio de outros grupos, e não é de hoje a reivindicação de que ela seja narrada da perspectiva dos que foram violentados. A referência histórica da Colônia Africana, atravessada pela Ancestralidade e o Território, ambos Valores Civilizatórios Afro-brasileiros (TRINDADE, 2010), foi considerada importante para fazer parte do documentário por grande parte dos estudantes. 0 aluno, ao enlaçar na sua explicação o bem cultural Academia Samba Puro com a História da presença negra no Partenon, toma para si o lugar de interlocutor e causa fissuras (RIBEIRO, 2017) na narrativa histórica hegemônica por meio da narrativa histórica situada. Em outro fragmento do documentário, as alunas e alunos explicam a documentação analisada: matérias do Jornal Zero Hora entre os anos de 1969 e 1986, que narram a trajetória da Irmã Nelly na Vila Maria da Conceição e a construção da Pequena casa da Criança:

V.: Irmã Nelly, uma freira que tinha apenas 20 anos, estava em busca de ajudar o morro, a comunidade. Ela botou sua cara à tapa, ajudando as pessoas mais carentes da Doca das Frutas. Logo após o despejo, as pessoas subiram para o morro que se chamava Vila Maria 
Degolada. Irmã Nelly, após subir o morro começou a falar, a explicar para as pessoas, que Maria Degolada era diferente de Maria da Conceição, pois aí mudou o nome da Vila.

Irmã Nelly tem uma grande importância para os moradores da Vila Maria da Conceição. Fundadora da pequena Casa da Criança, que começou em uma casinha de madeira construída com o mutirão da comunidade. Dona Tereza, em seu depoimento, conta: "A irmã Nelly bah... A Irmã Nelly ia na Doca ${ }^{8}$ ajudar nós... fazer missa no carro capela... nós saímos da Doca obrigados, veio a prefeitura, e a polícia... eu sei que ela criou um monte de gurizada ai...tudo junto com ela na Pequena Casa". A expressão "botou sua cara a tapa" foi usada pela aluna, pois, em uma das matérias de jornal pesquisadas, Irmã Nelly dá uma entrevista bastante contundente na qual denuncia o assassinato pela polícia de um menino, menor de idade e desarmado, na Vila Maria da Conceição. Para esse fato, um aluno fez um rap, cantado por ele no documentário:

(T.:)

De fuzil

Ele viu

Um pretinho morrer

Assassinado

'Bota uma arma aí'

Tava armado

Puxou o dedo no gatilho do menor já morto

Deu dois tiros

'Esse daí é troco'

Ho Há

Encostou o camburão

'Corre Corre!'

'Até quem não é envolvido, irmão!'

'Por quê?'

8 Doca das Frutas, vila situada onde hoje fica a Rodoviária de Porto Alegre. 
'Se tu fica paga pra ver!'

'Não vai ser eu que vou morrer'

Porque aqui eu vi vários manos ser morto

Vários mano ser preso

E nego tava estudando

O rapé, no documentário, entrecortado pela explicação de outro aluno, que situa a fonte histórica que traz essa informação: a denúncia de Irmã Nelly aos jornais. Assim, aponta a importância da denúncia da violência policial na periferia. Em outro momento do documentário, o fragmento da matéria de jornal aparece, com tempo para leitura da mesma, ao som de um samba enredo em homenagem à Irmã Nelly.

G.: E no outro dia a notícia saiu no jornal dizendo que o menino estava armado, mas a Irmã Nelly viu tudo e deu um depoimento dizendo que era mentira tudo isso. E é por isso que a Irmã Nelly é importante pra comunidade: ela mostra como é que a polícia trata os moleque do Morro.

Após a explicação do colega, o rap retorna com um apelo:

(T.:)

A favela

Chora

Pede paz

A favela

Chora

Pede paz

Eles tão me roubando muito mais

Eles tão me roubando

Muito, muito mais

Aqui o lugar de fala, enquanto lócus social e experiência compartilhada, é reivindicado como morador de periferia: é a favela que chora, pede paz. Essa é uma identidade reforçada pelas alunas e alunos a todo tempo: só quem é da "quebrada" sabe. No morro, chama a atenção o quanto a branquitude é nomeada, tanto como uma afronta ou ofensa em óbvia reação aos insultos racistas, quanto a partir de outra perspectiva. Entre as moradoras da comunidade, há situações em que a branquitude é nomeada 
para animar uma amiga: "Branca, tu é guerreira, tu vai sair dessa!" A diferença racial não é negada, ao contrário, é demarcada. O que se compartilha é o marcador social "classe". E "eles", quem são? Os que estão Ihe roubando muito mais? Com certeza o aluno se refere à ação do Estado através da polícia, que justifica os assassinatos nas favelas - no tempo da Irmã Nelly, usavam como argumento os pequenos furtos realizados pelos meninos de periferia e, hoje, a justificativa é da guerra às drogas para executar vidas negras e pobres.

\section{PROTAGONISMO E NARRATIVA HISTÓRICA SITUADA}

O documentário traz um conjunto de depoimentos de moradoras e moradores da Vila Maria da Conceição, em que, ao contar suas histórias de vida e informar sobre seus locais de origem, contam também sobre a formação populacional da Vila Maria da Conceição. Vieram da Colônia Africana, de Rio Grande, dos despejos das "vilas de malocas", Doca das Frutas e Santa Luzia, onde foi fundada nossa escola, que era pequena, comunitária e de madeira. Os depoimentos ainda trazem, através da experiência e dos saberes das moradoras e moradores, a História do Batuque e da Umbanda na cidade de Porto Alegre e a atuação da Pastoral do Negro na construção do Dia da Consciência Negra na comunidade.

Após essas falas, no documentário As Marias da Conceição: Por um ensino de História Situado, o último grupo explica as fontes históricas pesquisadas. 0 grupo pesquisou documentos do período escravista: um inventário e doze cartas de Liberdade. Mas, antes da explicação, ao som dos tambores, é anunciado por uma aluna:

L.: O Morro Maria da Conceição, ele é um quilombo, porque ele tem coisas de matriz africana: o carnaval, a religião de batuque, a umbanda... E também é que nem os quilombos antigos, além de só ter negros, também tem os brancos pobres. Que antigamente também era assim, brancos pobres também iam pros quilombos.

Novamente, o Lugar de Fala é anunciado a partir da experiência compartilhada pelos moradores de periferia, no caso, a Vila Maria da Conceição. Mas a fala é potente ao evocar a historicidade dessa experiência coletiva de aquilombamento. Trabalhamos a partir do conceito de Quilombo presente no samba enredo do Mestre Paraquedas: É Morro, é Favela, é Gueto, é Quilombo, que conversa com o conceito de Quilombo de Beatriz Nascimento (apud RATTS, 2007). Do seu Lugar de Fala de historiadora negra ligada ao coletivo do qual fazia parte, ao se debruçar sobre comunidades negras rurais, onde a questão fundamental do direito à terra está colocada, mostra a intenção de seu trabalho. Os territórios quilombolas reconhecidos pelo Artigo 68 da Constituição Federal se conectam às investigações de 
Beatriz Nascimento. As comunidades remanescentes de Quilombos, embora sob constante ameaça e disputa com os setores do agronegócio, evocam esse discurso histórico para afirmar sua existência. Isso tem Ihes garantido a sua existência concreta, mesmo com os entraves no que diz respeito à titulação das terras. É o sonho de Beatriz Nascimento:

Gostaria de dar a este trabalho o título de 'a memória ou a oralidade histórica como instrumento de coesão grupal', ou ainda 'A memória e a esperança de recuperação do poder usurpado.' Esta maleabilidade de títulos possíveis talvez se deva ao fato de este não ser, ainda, um trabalho concluído. Trata-se de um estudo prolongado e exaustivo. Dizendo isto, estou tentando transmitir minha experiência de pesquisa sobre os quilombos brasileiros, pesquisa que tomou, no projeto, o título de 'Sistemas sociais alternativos organizados pelos negros - dos quilombos às favelas'. Este projeto é também um grande sonho. Cientificamente falando, pretendemos demonstrar que os homens e seus grupamentos, que formaram no passado o que se convencionou chamar 'quilombos', ainda podem e procuram fazê-los. Não se trata de, no meu entender, exatamente de sobrevivência ou de resistência cultural, embora venhamos a utilizar estes termos, algumas vezes como referência científica. 0 que procuramos neste estudo é a 'continuidade histórica', por isso me referi a um sonho (1982, p. 165, apud RATTS, 2006).

A historiadora negra brasileira, Beatriz Nascimento (apud RATTS, 2006), identificou, na seletividade dos temas pesquisados no Curso de História, a orientação para a produção de conhecimentos que reforçam essas imagens de controle. Percebeu, logo que entrou na faculdade, que a História dos negros no Brasil se restringia à escravidão e que isso tinha um impacto na vida das pessoas negras. Desse modo, a História, como discurso legitimado sobre o passado, precisaria ser disputada, pois essa relação com o poder é determinada por quem pode representar e quem é representado. Abordar a História Afro-brasileira a partir da escravização dos corpos negros pode ser um desserviço, dependendo da maneira com que é feita. Por outro lado, não temos o direito de ocultar, minimizar ou "varrer para baixo do tapete" que a História do Brasil é marcada a ferro no que tange à escravização de Africanos e seus descendentes. Djamila Ribeiro (2017, p. 89) aponta que:

Numa sociedade como a brasileira, de herança escravocrata, pessoas negras vão experienciar racismo do lugar de quem é objeto desta opressão, do lugar que restringe oportunidades por conta desse sistema de opressão. Pessoas brancas vão experienciar do lugar de quem se beneficia dessa mesma opressão. Logo ambos os grupos podem e devem discutir essas questões, mas falarão de lugares distintos. Estamos dizendo, principalmente, que queremos e reivindicamos que a História sobre escravidão no Brasil seja contada por nossas perspectivas também e não somente pela perspectiva de quem venceu, para parafrasear Walter Benjamim, em Teses sobre o conceito de História. 
Estamos apontando para a importância da quebra de um sistema vigente que inviabiliza estas narrativas.

A narrativa histórica situada pode contribuir na elaboração coletiva desses traumas históricos. Mas é preciso estar alerta para manejar tais informações, pois se trata de um tema sensível para alunas e alunos negros. Evitou-se encenar meninas negras atuando como escravizadas, pois seria obviamente violento para elas. Ao invés disso, construiu-se com as alunas e alunos um esquema com os sujeitos que aparecem nas fontes históricas, no qual todas as informações consideradas relevantes foram registradas, para que pudessem visualizar com maior facilidade as relações entre esses sujeitos, e assim produzir suas narrativas, já que se tratava de uma documentação densa e apresentada aos estudantes como réplica (xerox colorido) dos documentos originais. As alunas assim explicaram a documentação explorada:

Ke.: Nós estudamos sobre o inventário da Constância Rainieri, que era casada com Nicolau Rainieri. Eles juntos tinham 6 terrenos no Partenon. Temos aqui 12 cartas de liberdade dos escravizados que durou de 1863 até 1882.

K.: Virgilina, Enriqueta, Pedro da Nação Nagô e Joaquina da Nação Angola compraram suas próprias liberdades.

L.: América e Olímpia, filhas de Virgilina e Raul tiveram suas cartas de Liberdade compradas pelo Movimento Abolicionista.

AC.: Malvina, Rita, Julieta e Manuel Alexandre foram libertos em atenção e remuneração pelos bons serviços que têm prestado.

R.: Manoel continuou escravizado e sua profissão era padeiro.

L.: Enriqueta, mãe de Malvina, e Virgilina, mãe da América e Olímpia, que só tinha 5 meses, teve sua carta de liberdade comprada pelo Parthenon Literário.

AC.: $\mathrm{O}$ que nos chamou atenção nesse documento não é que a branca era boa e deixou herança em dinheiro para América para Olímpia e para Malvina.

K.: Outra coisa que chamou atenção nossa foi: as mães batalharam para dar melhores condições de vida para suas filhas.

L.: E que as mães conseguiram deixar pras filhas a sua carta de liberdade e uma herança.

R.: E que elas aprendessem a ler e escrever e assinassem o documento com os seus próprios punhos, coisa que muitos brancos não faziam na época.

Nada que Constância Rainieri tenha feito: deixar em testamento cartas de liberdade e herança, ou batizar as meninas, filhas de suas escravas, na crisma, convenceu as alunas de que ela era uma boa 
pessoa. Não foram suas ações que chamaram a sua atenção. Ela era uma proprietária de escravos, a quem as alunas se referiam como "a branca". Aqui, a branquitude é situada historicamente. Por outro lado, a agência das "mães" escravizadas é ressaltada: foram elas que lutaram para que suas filhas tivessem melhores oportunidades. Com essa análise, as alunas se aproximam do pensamento de Lélia Gonzalez, quando se refere à "mãe preta":

Lélia Gonzalez, ao valorizar a resistência desenvolvida pela 'mãe preta', no período escravista, muitas vezes, realizada através da negociação, assegurando com a ação sua sobrevivência, a de sua prole e a de seus parceiros, evidencia o movimento do sujeito resistindo à objetificação que Ihe é imposta. Dito em outras palavras, a autora ilumina as estratégias desenvolvidas pelas mulheres negras escravizadas para enfrentar o processo de dominação/exploração que procurava mantê-las como outro/escravo/objeto (CARDOSO, 2014, p. 48).

Quanto "à branca", no documentário O Grande Tambor, do Coletivo Catarse, uma senhora quilombola afirma que as pessoas brancas dizem que os negros são descendentes de escravos, mas não dizem que eles (os brancos) são descendentes de escravizadores. Os documentos do período escravista, se interrogados de uma perspectiva antirracista, podem por um lado desvelar as estratégias de resistência das pessoas escravizadas e, por outro, racializar o escravizador, expor sua branquitude. As reflexões das alunas fazem com que nos defrontemos com nosso Lugar de Fala, atravessado pelo privilégio branco, e com o cuidado que é preciso para se relacionar com as alunas e alunos sem impor de forma colonizadora nossos valores e concepções de mundo e conhecimento. Ao mesmo tempo, nos preocupa nesta pesquisa não assumir uma posição de protagonistas em processos nos quais as alunas e alunos construíram narrativas históricas sobre o lugar em que moram. Elas e eles são os sujeitos que, a partir das suas experiências de vida - o que inclui as aulas de História -, construíram essas reflexões. Nesse sentido, o trabalho como professora foi compartilhar procedimentos e métodos de análise. Fazer perguntas. Munidos das informações de contexto histórico, amparadas em fontes e das ferramentas analíticas do Pensamento Feminista Negro, elaboraram suas narrativas. No final do documentário, perguntadas como são as mulheres da Vila Maria da Conceição hoje em dia, elas respondem:

AC.: Ah elas são fodas!

L.: Acordam de madrugada pra poder dar sustento pros seus filhos...

AC.: Saem assim, com perigo, tipo, na vila assim do jeito que tá, pra poder dar maior conforto.

R.: Tão sempre dando o melhor pra ter as coisas dentro de casa, pra não deixar faltar nada pros seus filhos. 
K.: E as crianças indo pra escola para ser alguém na vida!

L.: E muitas vezes não conseguem...

AC.: Às vezes na chuva, no frio, de madrugada...

L: De madrugada! 0 sol nem saiu ainda, o sol nem quer sair e elas já tão na rua! Pra poder pegar o Caldre Fião cheio!

AC.: Pois é...

Quem são as Marias da Conceição? São as mulheres que habitavam o morro no passado? São as mães, tias, avós, que as alunas definem como "foda", guerreiras que batalham para dar o melhor para seus filhos? São as moradoras que deram seus depoimentos no documentário? Ou seriam ainda as alunas que contam esta história? Acreditamos que são todas elas. E também todas aquelas que, ao assistir o documentário As Marias da Conceição - Por um Ensino de História Situado, sentiram que também compartilham aquela experiência, que aquele também é seu lugar social, seu lugar de fala.

\section{REFERÊNCIAS}

ANHORN, C. T. G. Teoria da História, didática da História e narrativa: Diálogos com Paul Ricoeur. Revista Brasileira de História, São Paulo, v. 32, n. 64, p. 187-210, 2012.

BAIRROS, L. Nossos feminismos revisitados. Revista Estudos Feministas, Florianópolis, v. 3, n. 2, p. 458-463, 2 sem. 1995.

CAPUZZO, N. Miséria quem te gerou? Porto Alegre: Editora Sulina, 1964.

CARDOSO, C. P. Amefricanizando o Feminismo: O Pensamento de Lélia Gonzales. Revista Estudos Feministas, Florianópolis, v. 22, n. 3, 320, p. 965-986, set./dez. 2014.

CARNEIRO, S. Enegrecer o Feminismo: A situação da mulher negra na América Latina a partir de uma perspectiva de gênero. Rio de Janeiro, 2011. Disponível em: <http://arquivo.geledes.org.br/em-debate/ sueli-carneiro/17473-sueli-carneiro-enegrecer-o-feminismo-a-situacao-da-mulher-negra-naamerica-latina-a-partir-de-uma-perspectiva-de-genero>. Acesso em: 23 set. 2015. 
CRENSHAW, K. A urgência da Interseccionalidade. TED, 2016. Disponível em: <https://www.ted.com/ talks/kimberle_crenshaw_the_urgency_of_intersectionality?language=pt-br\#t-698194>. Acesso em: 06 mar. 2018.

EVARISTO, C. Conceição Evaristo: 'minha escrita é contaminada pela condição de mulher negra'. Entrevista de Juliana Domingos de Lima. Revista Nexo, São Paulo, 26 maio 2017. Disponível em: <https://www.nexojornal.com.br/entrevista/2017/05/26/Concei\%C3\%A 7\%C3\%A30-Evaristo-\%E2\%80\%98minha-escrita-\%C3\%A9-contaminada-pela-condi\%C3\%A7\%C3\%A30de-mulher-negra\%E2\%80\%99>. Acesso em: 06 mar. 2018.

GONZALEZ, L. Racismo e sexismo na cultura brasileira. In: SILVA, L. A. et al. Movimentos sociais urbanos, minorias e outros estudos. Ciências Sociais Hoje, Brasília, ANPOCS, n. 2, p. 223-244, 1983.

RAMOSE, M. B. Globalização e Ubuntu. In: BOAVENTURA, S. S.; MENESES, M. P. Epistemologias do Sul. Coimbra: Almedina, 2009. Capítulo 4 pág. 135 a 176

RATTS, A. Eu sou Atlântica: sobre a trajetória de vida de Beatriz Nascimento. São Paulo: Imprensa Oficial, 2006.

RECH, T. B. Casas de Religião de Matriz Africana em Porto Alegre: Territorialidades Étnicas e/ou Culturais a partir da Antiga Colônia Africana. 2012. 126 f. Dissertação (Mestrado em Geografia -Instituto de Geociências, Universidade Federal do Rio Grande do Sul) - Porto Alegre, Rio Grande do Sul, 2012. Disponivel em: <https://lume.ufrgs.br/handle/10183/56235>. Acesso em: 15 nov. 2018.

RIBEIRO, D. Feminismo Negro: Violências históricas e Simbólicas. Ponte Jornalismo, 2015. Disponível em: <http://ponte.org/feminismo-negro-violencias-historicas-e-simbolicas>. Acesso em: 14 out. 2015.

RIBEIRO, D. 0 que é lugar de fala. Belo Horizonte: Letramento; Justificando, 2017.

RIO GRANDE DO SUL. Arquivo Público do Estado do Rio Grande do Sul. Maria Degolada - Mito ou Realidade? Porto Alegre: EST, 1994.

RUFINO, L. Exu e a Pedagogia das Encruzilhadas sobre conhecimentos, educações e Pós Colonialismo. In: SEMINÁRIO INTERNACIONAL AS REDES EDUCATIVAS E AS TECNOLOGIAS: MOVIMENTOS SOCIAIS E EDUCAÇÃO, 8., 2015, Rio de Janeiro. Anais... UERJ: Rio de Janeiro, jun. 2015. Disponível em: <https:// pt.scribd.com/document/356170801/Exu-e-a-Pedagogia-Das-Encruzilhadas>. Acesso em: 08 mar. 2017. 
TRINDADE, A. L. Os Valores Civilizatórios e a Educação Infantil: uma contribuição Afro-brasileira. In: BRANDÃO, A. P. ; TRINDADE, A. L. (Org.). Modos de Brincar: Caderno de atividades, saberes e fazeres. Rio de Janeiro: Fundação Roberto Marinho, 2010. p. 11-15.

VALENTIM, S.; TRUCK, G. O Grande Tambor. Coletivo Catarse, Porto Alegre, 2012. Disponível em: <https://www.youtube.com/watch?v=xIL6Hfq4ZTw>. Acesso em: 10 abr. 2018.

VARELA, J.; ALVAREZ-URIA, F. A maquinaria escolar. Teoria e Educação, Porto Alegre, Pannonica, n. 6, p. 68-96, 1992. 